\title{
El arma de Caballería del Ejército Nacional de Colombia: avances en la inclusión de mujeres ${ }^{1}$
}

https://doi.org/10.21830/9789585318304.06

\author{
Édgar Camilo Bello Mora ${ }^{2}$ \\ Félix Andrés Bejarano Bejarano ${ }^{3}$ \\ Rodrigo Calderón Rojas ${ }^{4}$ \\ Diego Armando Guerrero Zabala 5 \\ Escuela de Armas Combinadas del Ejército \\ Andrés Eduardo Fernández-Osorio ${ }^{6}$ \\ Escuela de Aviación del Ejército
}

\section{Resumen}

La investigación de la que surge este capítulo analizó la cultura y las tradiciones del arma de Caballería del Ejército Nacional de Colombia, para determinar si se encuentra preparada para aceptar a las mujeres oficiales en igualdad de condiciones y proporciones que los hombres. Para esto, se realizó una revisión bibliográfica descriptiva y compilatoria. Se evidenciaron avances

1 Este capítulo presenta los resultados del proyecto de investigación "Construcción de los roles de la mujer militar en el posacuerdo" del Semillero de Investigación Arbitrium, Grupo de Investigación para la Capacitación Militar (GICAM), de la Escuela de Armas Combinadas del Ejército, categorizado en C por Minciencias y con código de registro COL0160714. Los puntos de vista y los resultados de este artículo pertenecen a los autores y no reflejan necesariamente los de las instituciones participantes.

2 Mayor del Ejército Nacional de Colombia. Especialista en Administración de Recursos para la Defensa Nacional (Centro de Educación Militar). Profesional en Ciencias Militares (Escuela Militar de Cadetes "General José María Córdova").

3 Mayor del Ejército Nacional de Colombia. Especialista en Administración de Recursos para la Defensa Nacional (Centro de Educación Militar). Profesional en Ciencias Militares (Escuela Militar de Cadetes "General José María Córdova").

4 Mayor del Ejército Nacional de Colombia. Especialista en Administración de Recursos para la Defensa Nacional (Centro de Educación Militar). Profesional en Ciencias Militares (Escuela Militar de Cadetes "General José María Córdova").

5 Mayor del Ejército Nacional de Colombia. Especialista en Administración de Recursos para la Defensa Nacional (Centro de Educación Militar). Profesional en Ciencias Militares (Escuela Militar de Cadetes "General José María Córdova").

6 Teniente Coronel del Ejército Nacional de Colombia. PhD en Derecho y Ciencia Política (Universidad de Barcelona). Magíster en Economía, Estado y Sociedad: Política y Seguridad (University College London). Magíster en Relaciones Internacionales (Higher School of Economics, Moscow). Investigador del Grupo de Investigación en Aviación Militar de la Escuela de Aviación del Ejército. Orcid: https://orcid.org/00000003-0643-0258 - Contacto: andres.fernandez@buzonejercito.mil.co 
significativos en materia de inclusión de la mujer en las Fuerzas Armadas a nivel mundial, especialmente, en Estados Unidos, España y Argentina. Se observó que en Colombia está establecido el pleno acceso de mujeres a todas las Armas de la institución, no obstante, aún persisten factores que limitan el debido desarrollo de las mujeres en el Ejército: la falta de experiencia en labores operativas, el lenguaje simbólico militar de tradición masculina y la falta de ejecución de políticas públicas para la mujer militar.

Palabras clave: arma de Caballería; Ejército de Colombia; equidad de género; inclusión; mujer militar

\section{Introducción}

Esta investigación incorpora una serie de experiencias propias que se complementaron y enriquecieron con la compilación y análisis bibliográfico de información histórica, institucional, técnica y científica. Esta combinación permite apreciar diversas ideas y formas de posicionarse frente a lo que configura el género femenino en Colombia y su lucha por consolidarse plenamente en una institución como el Ejército Nacional, específicamente, en el arma de Caballería.

Ahora bien, es imperativo iniciar con un breve recuento de la emancipación femenina como un proceso que paulatinamente se ha encargado de empoderar a la mujer y ubicarla en diversos escenarios dentro de lo social, político, económico y cultural (a nivel mundial) como un sujeto activo en lo público. Hace más de 98 años, un grupo de mujeres en Estados Unidos, que trabajaban en una fábrica textil en Nueva York, tuvo la iniciativa de exigir igualdad de condiciones laborales respecto a los hombres, ya que ellas eran sometidas a una jornada más larga y con menor remuneración. A partir de ese momento, no pasó mucho tiempo sin que las mujeres empezaran a rebelarse frente a estas situaciones de desigualdad y discriminación, con lo cual le dieron lugar a un cambio de paradigma, pues se involucraron en hechos políticos, revoluciones, luchas sociales y económicas para conseguir el lugar que hoy la mujer ha ganado a lo largo de los años (Robelo, 2015).

De acuerdo con Cely (2019), el segundo hecho histórico que aporta significativamente a la autonomía, libertad y libre desarrollo de la mujer en la sociedad es la creación y aprobación del consumo de la píldora anticonceptiva, hecho que significó un gran apoyo que permitió la planificación familiar desde el punto de vista farmacéutico. Otro hecho que acentuó la ruta hacia el empoderamiento femenino fue el derecho al voto, que originó el reconocimiento de la opinión de la mujer desde en un sentido democrático y amplió su participación como ciudadana. Posteriormente, se dio el ingreso a la educación superior y la oportunidad de participar en espacios del sector público. 
El inicio del proceso de emancipación femenina es indiscutiblemente la vinculación de la mujer al mercado laboral, como una dura batalla en la búsqueda de independencia económica y autonomía. Un hito que marcó la historia de la inclusión laboral femenina se originó durante la Revolución Industrial, porque se cambió la visión y la forma en que las mujeres empezaron a encarar a la sociedad. Aun cuando esta vinculación a la esfera pública trajo consigo nuevas conceptualizaciones de lo femenino, Fonseca (2017) manifiesta que este primer paso fue "visto como algo raro, y no conforme con esto, a la hora de realizar un trabajo, se les exigían más que a los hombres en relación a las obligaciones que surgían del vínculo laboral".

Es así como el tema de la lucha por los derechos de las mujeres en la búsqueda de equidad social ha sido bastante polémico a través de la historia. Aspectos como el modelo patriarcal imperante, el machismo, el sexismo y la manera como el género femenino ha ido escalando y superando barreras en diferentes ámbitos, incluido el escenario militar, implican no pocas dificultades para las mujeres que se están formando como oficiales y suboficiales en diferentes escuelas militares del mundo y de Colombia, en un ambiente que tradicionalmente era considerado masculino (Uscátegui, 2015).

De esta manera, Camacho y Cabrera (2015) agregan que la incorporación de la mujer en las Fuerzas Armadas ha generado controversia, ya que el ejército y la guerra se han considerado espacios masculinos, donde las mujeres han ingresado por presiones extrínsecas y cuyas labores se han limitado a lo logístico y administrativo. Todo lo anterior está relacionado con el constructo social llamado género:

Un elemento base del proceso de identificación de todo sujeto, que tiene como soporte una realidad biológica (el ser hombre o mujer) en torno a la cual se estructuran expectativas, comportamientos, requerimientos, necesidades. El género no es un elemento aislado, sino que hace parte de un conjunto atravesado por variables históricas, psicológicas, sociales y culturales. (Camacho \& Cabrera, 2015, p. 13)

"No se nace mujer: se llega una a serlo", frase citada por la filósofa y activista francesa Simone de Beauvoir en 1949, considerada como una de las más grandes pensadoras feministas del siglo XX. Esta pensadora, en su obra El segundo sexo, describe el proceso vital de las mujeres con el inicio de una definición sexual asignada biológicamente (útero, ovarios), luego la infancia, hasta la vejez, a fin de mostrar cómo a lo largo de su vida la mujer adquiere un sentido de inferioridad en la sociedad con respecto al sexo opuesto. Esta posición de inferioridad se ha naturalizado mediante la imposición de estereotipos, roles de género y espacios que 
definen lo que es ser hombre y ser mujer. Es así como históricamente el hombre ha ocupado el espacio público en donde logra poder, dinero y reconocimiento, mientras que a las mujeres se le han asignado roles de cuidado y protección en el ámbito familiar (Ventura, 2015).

En tal caso, como argumenta Alioni (2016), la institución militar se considera como fundante y paradigmática en la vida social, como lugar político de producción y reproducción de sujetos (hombres y mujeres) modulados en prácticas de subordinación, lo que genera tensiones al instaurar cuestiones de género. Es aquí donde cobra importancia el concepto de igualdad y equidad de género. En palabras del mayor general Ricardo Gómez (2015): “en una situación de equidad de género, los derechos, responsabilidades y oportunidades de los individuos no se determinan por el hecho de haber nacido hombre o mujer", sino que la equidad propone un trato justo para ambos sexos, independientemente de sus diferencias biológicas (Gómez, 2015).

Esta perspectiva de género llegó también a las Fuerzas Armadas: Olmo (2017) hace referencia a que la incorporación de la mujer al servicio de armas no es solo el reflejo de una realidad social en la búsqueda de equidad, sino también la respuesta a una necesidad operativa real de las Fuerzas Armadas. A su vez, afirma:

Como ha señalado el teniente general sueco Anders Lindström, "una perspectiva de género es vital para el éxito de nuestras operaciones". La experiencia demuestra que la participación de las mujeres en la vanguardia de las misiones, por peligrosas que sean, "nos hará tener unas mejores posibilidades de éxito". (Olmo, 2017, p. 3)

De esta manera, en el 2000 la Resolución 1325 del Consejo de Seguridad de Naciones Unidas expresó el objetivo de una "plena participación de las mujeres en todos los esfuerzos por el mantenimiento de la paz y la seguridad". Desde entonces, distintos gobiernos miembros de la Organización del Tratado del Atlántico Norte (OTAN) han promovido con éxito desigual el alistamiento de las mujeres (Olmo, 2017). Sin embargo, su situación y el alcance de su representatividad varían significativamente según cada país. Dentro del conjunto de Estados pertenecientes a la OTAN, los ejércitos que tienen una incorporación completa de mujeres en las instituciones castrenses representan cerca del $11 \%$, mientras que en América Latina apenas sobrepasaban el $4 \%$ con una alta representatividad de mujeres en los ejércitos en 2010 (Carreiras, 2018).

En Colombia, la participación del género femenino en el Ejército Nacional representa el $11,9 \%$ del total de personal activo, debido a un proceso que tuvo origen en 1976, con el ascenso al grado de oficiales en el cuerpo administrativo de 
doce mujeres que se incorporaron inicialmente en las especialidades de bacteriología, medicina y odontología. En 2015, eran 6.363 las mujeres que pertenecían a la institución en diferentes roles como oficiales, suboficiales y civiles (Uscátegui, 2015); cifra que se mantiene constante hasta el día de hoy.

Cabe anotar que el Ejército Nacional de Colombia se estructura en tres cuerpos. En primera instancia, se encuentra el cuerpo de las armas, que son aquellos hombres o mujeres que ingresan a cursar la carrera militar en las escuelas de formación, en otras palabras, son los profesionales en ciencias militares. En segundo lugar, está el cuerpo administrativo, que corresponde a todas las personas que teniendo un título profesional ingresan a formar parte del Ejército Nacional desempeñando los servicios que correspondan a su profesión. El tercer cuerpo está conformado por los profesionales de la Reserva de las Fuerzas Armadas de Colombia, quienes están vinculados al Comando General de las Fuerzas Militares del país. A la Reserva pertenecen los ciudadanos con título de formación universitaria completa que de manera voluntaria se vinculan al Ejército, la Armada o la Fuerza Aérea a través de cursos especiales ordenados y programados por el Ministerio de Defensa.

El cuerpo de las armas del Ejército Nacional de Colombia en la actualidad está conformado por Infantería, Caballería, Artillería, Ingenieros, Inteligencia, Comunicaciones, Aviación, Logística, Fuerzas Especiales y Acción Integral. De igual forma, tienen subdivisiones, por ejemplo, está la Infantería liviana, mediana y pesada; la Caballería montada y la mecanizada; la Artillería antiaérea; los Ingenieros de mantenimiento, de contracción y de rescate; la Inteligencia humana y la técnica; la Logística de transportes, de armamento y de intendencia (Ejército Nacional de Colombia, 2019).

Retomando a Carreiras (2018), este autor agrega que el proceso de inclusión de personal femenino en las Fuerzas Militares, para el caso del Ejército en el cuerpo de las armas, es un hecho significativo que, por un lado, evidencia el espacio y el rol que las instituciones militares ocupan en las diferentes esferas sociales y, por otro, cuáles son sus procesos internos de transformación organizacional. De la misma forma, observa que en "muchos países la presencia de mujeres ha servido de catalizador de la convergencia entre las esferas militar y civil y ha contribuido", de cierta manera, a minimizar el aislamiento de las Fuerzas Armadas y, a su vez, a democratizar las instituciones militares.

Ahora bien, surgen varias preguntas; ¿dentro de estos casos de éxito se encuentra Colombia?, ¿`cómo ha sido históricamente el proceso de incorporación de las mujeres a una institución de tradición masculina como lo es el Ejército Nacional?, ¿en realidad se ha logrado alcanzar una verdadera equidad de género 
entre los militares activos hombres y mujeres, en relación con los diferentes roles que desempeñan dentro del Ejército Nacional?, ¿`cuáles son los aciertos, desaciertos y los retos que enfrenta la institución para garantizar la plena incorporación de las mujeres en su organización? Este trabajo pretende ahondar en estos interrogantes con el fin de ampliar las perspectivas y proponer algunas respuestas.

En virtud de lo anterior, este documento investigativo se propone como objetivo analizar si la cultura y la tradición del Ejército Nacional, en especial, en el arma de Caballería, se encuentra preparada para vincular a la mujer oficial en igualdad de condiciones que los hombres oficiales. Para esto, se desglosarán tres secciones. En la primera se abordará cómo ha sido la incorporación de las mujeres en las Fuerzas Armadas en el contexto internacional. En segundo lugar, se pasará al plano nacional y se describirá histórica y estadísticamente el proceso de inclusión de las mujeres en el Ejército Nacional de Colombia, con especial énfasis en el arma de Caballería. Por último, se realizará un análisis de los aciertos, desaciertos y retos que se deben asumir para que exista una verdadera equidad entre los hombres y las mujeres que conforman las filas de esta especialidad en el Ejército Nacional.

\section{Método}

Se realizó una búsqueda de información científica sobre los temas relacionados con la incorporación de la mujer en las Fuerzas Militares. Los artículos se tomaron de bases de datos calificadas (Redalyc, Dialnet y JSTOR, principalmente) y, para ser seleccionados, se verificó que cumplieran con los siguientes criterios: artículos de revistas indexadas o categorizadas por la plataforma Publindex, reportes e informes de investigación, libros y capítulos con información relevante sobre el proceso de inclusión de la mujer en las Fuerzas Militares a nivel mundial y nacional, así como información sobre aciertos, desaciertos en la incorporación y aspectos históricos, historiográficos, normativos y sociopolíticos que aborden el rol de la mujer militar y la participación femenina en misiones de paz, entre otros. El trabajo se sustenta, en consecuencia, en una revisión bibliográfica de corte descriptivo y compilatorio, pues se basa en la recolección, selección de información y posterior análisis y procesamiento cualitativo de esta. Así, se cuenta con un corpus de documentos que aportan a la construcción de una temática amplia acerca del tema de las mujeres militares en Colombia. 


\section{Resultados}

\section{Las mujeres en armas: en búsqueda de la igualdad}

La participación de las mujeres en las instituciones armadas ha sido permanente a lo largo de la historia. En casi todas las guerras, las mujeres han realizado tareas que, si bien son esenciales para el desarrollo de las instituciones armadas, no estaban sujetas a la disciplina militar; por tanto, no fueron consideradas bajo la responsabilidad de las fuerzas, con el fin de uniformarlas, acuartelarlas o remunerarlas (Gutiérrez Valdebenito, 2000). El proceso de ingreso sistemático de mujeres a la vida militar estuvo precedido históricamente de su participación en las luchas de la Independencia, para el caso latinoamericano, en el siglo XIX (Alioni, 2016; Lucero, 2009).

Solo a contar de la Primera Guerra Mundial, las mujeres comenzarán a desempeñarse bajo el mando militar en puestos diferentes a los de enfermería. La necesidad sin precedentes de contar con efectivos militares no fue el único motivo para organizar grupos femeninos; antiguos conflictos, por ejemplo, la Guerra Civil de los Estados Unidos de América, habían logrado, en gran medida, la movilización de la población femenina. En 1954, Treadwell observó que el proceso de industrialización de la sociedad y de la guerra era un requisito previo necesario para el reclutamiento de las mujeres. (Gutiérrez Valdebenito, 2000, p. 1)

Ya para el siglo XX, la guerra se había organizado y mecanizado al punto de requerir de un mayor potencial humano del que cualquier nación estuviese en condiciones de proveerle (Gutiérrez Valdebenito, 2000). Este requerimiento explicaría, en parte, la presencia de mujeres en las instituciones armadas. Esto supuso el quiebre de uno de los sitemas organizativos más tradicionales y básicos de occidente.

En este sentido, en la investigación realizada por Camacho y Cabrera (2015), se hace referencia al paradigma del guerrero masculino combatiente comentado por Karen O. Dunivin (1997), con respecto al cual se expresa que las fuerzas armadas se basan en la concepción del guerrero que da la vida por su pueblo y que tiene su fundamento en los símbolos a través de la historia, lo que excluye directamente a la mujer como género opuesto, asociado a la dadora de vida.

En relación a ello, puede referirse la emergencia de significaciones, que vinculadas a la función institucional, signaron en el pasado a las distintas organizaciones castrenses [...] como: "reserva moral de la nación", "guardianas de la defensa", "garantes de la 
seguridad interior”. Esta territorialidad simbólica, se correspondió también con la definición tradicional de un modelo normativo de sujeto deseable para la misión. Dicho modelo reeditado en la naturalizada persistencia de la relación entre masculinidad e identidad militar se constituyó a partir de universos femeninos-masculinos fragmentarios y excluyentes, y en cuanto tal, necesarios al sostenimiento del orden institucional consagrado. (Alioni, 2016, p. 14)

De ahí que algunas armas están enmarcadas por un simbolismo histórico, por el hecho de ser más antiguas o más expuestas, como es el caso de la caballería y la infantería, consideradas las armas que dieron origen a todo ejército.

Esto hace parte de la mística de la milicia, la cual asocia la infantería y la caballería al modelo de masculinidad hegemónico, al del héroe que ofrece su alma, vida y cuerpo en combate. Para Dunivin, las armas de combate "le dan al hombre la oportunidad de demostrar su masculinidad, y el rol de guerrero es una forma de probar su hombría”. Esto excluye a las mujeres, a quienes se les relegaba a labores de logística o apoyo. (Camacho \& Cabrera, 2015, p. 94)

En efecto, la llegada de la mujer como miembro activo de las fuerzas armadas ha significado un cambio de paradigma, una reconceptualización de lo que representa tradicionalmente ser hombre o ser mujer en la milicia, impulsada principalmente por movimientos feministas. Esto ha venido siendo posible luego de superada la prohibición del acceso de la mujer a las Fuerzas Armadas basada en particularismos para excluirlas, además de incoherencias y paradojas que se establecieron en el propio ordenamiento jurídico, sin ningún tipo de rigor científico, mediante la asignación de roles naturalizados, estereotipos y clichés (Rico y Casas, 2006); por ejemplo, se encasillaban en las capacidades físicas, los cambios hormonales o la falta de resolución frente al dilema de la vida o la muerte en una situación de combate (Gutiérrez Valdebenito, 2000). No obstante, con la promulgación de las constituciones que le dan acceso a la mujer en todos los espacios de la vida política y pública, se abrieron las filas.

La tarea de recuperar la historia se vuelve relevante, ya que mediante ella es posible identificar la producción histórico-social con la que los sujetos han conformado los sentidos, los ideales e ideologías en las instituciones, así como unos modos de percibir y vivir que, al instituirse, enmascaran relaciones de poder, conflictos y luchas que subyacen en las prácticas sociales (Alioni, 2016). De este modo, a continuación se recapitulan algunos casos de mujeres que participaron en los ejércitos de Estados Unidos y España, que se convierten en pioneras para la incorporación exitosa de las mujeres no solo en labores logísticas y administrativas, sino en los diferentes cuerpos de armas. Asimismo, se muestran diversos ejércitos latinoamericanos 
y cómo se ha presentado la inclusión de las mujeres en diversas armas, teniendo en cuenta que el fenómeno latinoamericano de las mujeres militares presenta unas rutas tardías de inclusión en igualdad de condiciones.

\section{Estados Unidos y España: una historia de los ejÉRCITOS CON PLENA INCLUSIÓN DE LAS MUJERES EN ARMAS}

Estados Unidos es un país que cuenta con una amplia historia respecto a la inclusión femenina en las fuerzas armadas. Téngase en cuenta que, a través de su desarrollo geopolítico, social, económico y cultural, se ha podido apreciar el heroísmo, empoderamiento y liderazgo de "muchas mujeres que han creído en las causas de la guerra y se han encaminado a la lucha por sus propios medios" (Uscátegui, 2015, p. 15).

Un ejemplo de ello lo representa Sybil Lidington, una mujer de tan solo 16 años de edad, que se vistió de valentía y montando su caballo "logró reclutar milicia para repeler el ataque de los británicos, y por más de 40 millas desconocidas logró esparcir la noticia. Actualmente hay una estatua conmemorando su valentía en Carmel (New York)" (Uscátegui, 2015).

No obstante, la primera mujer que registró un récord por su actuación en un combate fue Deborah Sampson, de Massachusetts, en 1781 o 1782. Ella decidió enlistarse en el Ejército Continental (Continental Army) con una falsa identidad, bajo el nombre de Robert Shurtliff. De esta manera, Sampson sirvió por seis años en la guerra de revolución, siendo herida en dos ocasiones. En una oportunidad, se curó a sí misma de una bala de fusil para no tener que ser atendida por médicos y así evitar que descubrieran su verdadera identidad. Así mismo, en 1866 Cathay Williams se alista en el Ejército de Estados Unidos con el nombre de William Cathay; fue la primera mujer afroamericana de quien se tiene constancia que sirvió en este Ejército. "Para 1898 se tenía conocimiento de muchas mujeres que se habían enlistado haciéndose pasar por hombres” (Uscátegui, 2015, p. 16).

Además de esto, en abril de 2016, el entonces presidente Barack Obama abrió todas las posiciones militares a las mujeres, incluidas las unidades de combate. Por esta razón, en la actualidad las mujeres se pueden enlistar como oficiales en la Academia Militar de West Point en el estado de Virginia y también pueden matricularse como suboficiales en la Escuela United States Army Sergeants Major Academy (Cuerpo de Marine, Ranger Course, Paracaidismo) (Agrelo, 2016).

En 1999 el Ministerio de Defensa de España decide adoptar el modelo de Ejército profesional, el cual estipula el principio de igualdad entre hombres y mujeres en la búsqueda de una equidad para consolidar una legislación igualitaria y 
progresista. Actualmente, de los 120.000 efectivos que existen en este país, 15.000 (el $12,7 \%$ ) son mujeres y hacen presencia en todos los cuerpos y escalas militares, inclusive, en los puestos de combate (Ministerio de Defensa de España, 2018).

Es importante resaltar que, en julio de 2019, la coronel Patricia Ortega se convirtió en la primera mujer general de las Fuerzas Armadas de la historia de España, con 56 años de edad; ella también fue la primera mujer en alcanzar el puesto de coronel del Ejército de Tierra. Además de esto, se destacan otras cifras: 133 tenientes coroneles, 2 capitanes de fragata y 241 comandantas (Epdata, 2019).

Asimismo, el Ejército español es considerado a nivel internacional como un ejemplo de integración de las mujeres militares (Caballud Hernando, 2014), pues es uno de los países con mayor nivel de igualdad de la OTAN (12,7\%), superando a Alemania con un 9,3\% en 2016, y a los Países Bajos, Italia y Reino Unido. Esto pone a España en el tercer lugar de mayor inclusión de la mujer dentro de los países miembros de dicha organización internacional, superada solo por Francia y EE. UU. (Ejército de España, 2018)

Actualmente, las mujeres militares en España pueden vincularse a todos los cuerpos y escalas, y llevar a cabo su carrera profesional en igualdad de condiciones a los hombres. De la misma manera, ellas también pueden participar en todas las misiones fuera del país y en las mismas condiciones y funciones que antiguamente eran solo asignadas a personal masculino.

\section{EJÉRCITOS LATINOAMERICANOS: DE LA INSTRUMENTALIZACIÓN FEMENINA A}

\section{LA IGUALDAD DE CONDICIONES PARA LAS MUJERES}

La situación en el continente americano dista mucho de la homogeneidad que se predica en Europa. Por una parte, un reducido grupo de países, entre ellos Estados Unidos (del que se expuso anteriormente), Canadá y México, incorporaron a las mujeres en las Fuerzas Armadas de manera temprana (Martín Martínez, 2009). Por otra parte, en el contexto sudamericano de consolidación democrática se desarrolló durante el comienzo del nuevo milenio un fenómeno por el que se incorporaron mujeres al frente de las funciones ministeriales en el área de Defensa en cinco países - Argentina, Colombia, Chile, Ecuador y Uruguay— casi simultáneamente. Esta innovación se establecía sobre la promoción internacional de los derechos de las mujeres y la búsqueda de cambios relacionados con las reformas en las Fuerzas Armadas, con un mayor control civil, transparencia en las gestiones y reestructuraciones internas de los ministerios. Todo este fenómeno de apertura se difunde sostenidamente desde los años setenta, con la incorporación femenina dentro de las fuerzas terrestre y aérea en Chile, lo que se replicó gradualmente en el resto de la región a partir de la década de los ochenta (Lucero, 2009). 
(...) un dato común es que la mayoría de los Estados sudamericanos incorporaron primero a las mujeres dentro del cuerpo profesional, encontrándose los escalafones más altos en el cuerpo de mando vedado para las mujeres. Esta característica reforzó el predominio del paradigma patriarcal, impactando la discriminación también al plano económico, ya que a menor jerarquía en el cargo ocupado, menor remuneración. (Lucero, 2009, pp. 41-42)

La divergencia temporal de la participación de las mujeres en los diversos ejércitos ha estado acompañada por una notable dispersión en cuanto a la posible carrera profesional a desempeñar por las mujeres en los diferentes ejércitos americanos. Existe un nutrido grupo de países en los que las mujeres pueden acceder a las fuerzas armadas y desempeñar en ellas cualquier puesto y alcanzar todos los empleos militares, sin apenas restricciones; aunque algunos de ellos no han facilitado esta posibilidad sino hasta fechas recientes. Este grupo lo integran El Salvador, Guatemala, México, Paraguay, Perú, Uruguay y Venezuela (Martín Martínez, 2009).

Cabe resaltar el caso de Bolivia, donde las mujeres pueden ingresar en la Fuerza Terrestre y allí desempeñar su carrera profesional sin ninguna restricción, mientras que en la Marina y la Fuerza Aérea tan solo pueden ocupar puestos administrativos (Martín Martínez, 2009).

Superados estos limitantes, la inclusión de las mujeres en los ejércitos es una tendencia global, aunque para los países latinoamericanos de forma lenta y más dispersa. Se ha avanzado en diagnosticar y debatir sobre la participación de la mujer en las fuerzas armadas, tanto que los estudios sobre la inclusión femenina en diferentes armas de los ejércitos ha sido positiva. (Bustamante, 2012)

\section{MÉXICO}

En México a lo largo del tiempo la mujer ha tenido una participación constante en las Fuerzas Armadas, siendo una compañera entrañable del hombre durante todo el proceso revolucionario, al integrarse en la guerra no solo como apoyo moral, sino como combatiente. De la Rosa (2019) hace un recuento de las mujeres que han marcado la historia de la milicia en este país:

- Doña Encarnación Mares, “Chonita”, subteniente del 10. Regimiento de Caballería, grado que irónicamente Venustiano Carranza le retiró luego de haber trabajado para su causa.

- Carmen Parra, "La coronela Alanís", veterana de la Revolución.

- Petra Herrera, alias "Pedro Herrera" que, aunque llegó a general, Pancho Villa no le dio el crédito por ser mujer. 
- Rosa Bobadilla, "La Coronela”, que estuvo en las filas zapatistas.

- Dońa Ramona R. viuda de Flores, "la Güera Carrasco".

- Amelia Robles Ávila (Amelio), que llegó a coronel al lado de Zapata.

- Valentina Ramírez, "la Leona de Norotal” o "Juan Ramírez", se unió junto a su padre a la causa maderista.

Sin embargo, fue en 1938 que el entonces presidente de los mexicanos Lázaro Cárdenas del Río aprobó la creación de la Escuela para Enfermeras del Ejército, adscrita al Hospital General Militar. En ese momento, se oficializó la incorporación de las mujeres en las Fuerzas Armadas bajo la especialidad de enfermería. Meses después se crearía el Cuerpo de Oficinistas del Ejército. De acuerdo con la Secretaría de Defensa Nacional de México (2019), durante las siguientes décadas, el proceso de inclusión de las mujeres se extendió a diferentes áreas del Ejército:

Servicio de Cartografía (1947), la Escuela Médico Militar (1973), la Escuela Militar de Odontología (1976), Coro y Orquesta del Ejército y Fuerza Aérea Mexicanos (1985) y la Dirección General de Fábricas (1990). Y al fin, en 1994, se otorgó por primera vez el grado de General Brigadier a una mujer. (Secretaría de Defensa Nacional de México, 2019)

Para el año 2015, el Ejército y la Fuerza Aérea de México sumaban 12.488 mujeres, desde soldados hasta generales. De la misma forma, en esa fecha la Marina incluía 8.900 mujeres militares bajo las especialidades de infantería de marina, paracaidismo, aviación, control de vuelo, búsqueda y rescate, meteorología y medicina (Esquivel \& Rodríguez, 2015).

Luego, a finales de 2018 una totalidad de 23.547 mujeres hacían parte activa de las filas del ejército mexicano, aunque fue en el 2007 que se permitió el ingreso de mujeres a las carreras de Piloto Militar e Ingeniero Militar. Ya en el 2013 se marcó un hito en la historia de la participación de la mujer en las fuerzas armadas de este país, al admitirlas en las armas de Artillería y Zapadores (Medellín, 2018).

Sin embargo, Esquivel y Rodríguez (2015) realizan una crítica a la manera como se ha venido realizando el proceso de incorporación de la mujer en las Fuerzas Militares de México, puesto que deficiencias de orden político evidencian una ausencia de legislación sólida y favorable sobre la equidad de género. Además, en el Ejército de este país persiste la dualidad y se incorpora a la mujer de manera masiva, sin que se tome en serio su rango y se aprecie su aporte.

\section{Argentina}

Argentina es uno de los países latinoamericanos que más ha avanzado en materia de inclusión militar femenina en la región. Se destaca que en la actua- 
lidad existen 21 oficinas de género en la institución militar, que se consolidaron mediante la Resolución 1238/09 de 2009, con el objetivo de garantizar el pleno goce de los derechos de las mujeres y el óptimo desarrollo de su carrera militar. De igual manera, en este país existe un Consejo para Políticas de Género del Ministerio de Defensa, que está conformado por diferentes instituciones públicas estatales y no estatales. A su vez, se encuentra el Observatorio sobre la Integración de la Mujer en las Fuerzas Armadas y el Departamento de Genero de la Fuerza Aérea Argentina, que buscan analizar y evaluar las distintas situaciones de las mujeres en la carrera militar, brindar orientación y recibir inquietudes relacionadas con cuestiones de género en el ámbito laboral, lo que permite poner en marcha acciones y estrategias que puedan brindar soluciones (Lucero, 2018).

Ahora bien, la incorporación de la mujer en la estructura militar de Argentina inicia en 1960, mediante la creación de la Escuela de Enfermería en el Ejército. A partir de ese momento, el resto de las Fuerzas se fue abriendo paulatinamente para permitir la debida inclusión femenina en el denominado cuerpo profesional: la Armada lo hace en 1980 y la Fuerza Aérea en 1982. No obstante, este avance en materia de género obedeció a la necesidad de contar con especialidades civiles necesarias en las áreas de medicina, enfermería, odontología, ingeniería, abogacía (Donadio, 2015).

Superado ese período de acoplamiento, años más adelante, en 1991, se creó la Escuela Militar de Oficiales de los Servicios para Apoyo de Combate y la Escuela de Suboficiales para Apoyo de Combate, así como otros institutos mixtos para el reclutamiento y la formación de oficiales y suboficiales profesionales. En este orden de ideas, ya para 1997, las mujeres tuvieron la posibilidad de ingresar a los institutos de formación de oficiales y suboficiales en las armas de apoyo de combate y apoyo de fuego, para posteriormente, a partir de 2013, vincularse a todas las armas de los elementos básicos de combate: Infantería y Caballería (Ministerio de Defensa de Argentina, 2019)

\section{Ecuador}

Siguiendo el fenómeno social de la década de los setenta, por aquel entonces Ecuador abrió camino a la posibilidad del ingreso voluntario de la mujer en la vida militar, inicialmente, como oficial de servicios. Las mujeres que ingresaron de esta manera, luego de un período de militarización, formaron parte de las Fuerzas Armadas como oficiales de sanidad o de justicia. La permanencia de estas mujeres en las Fuerzas Armadas estaba sujeta a ciertas limitaciones de ascenso a los grados superiores (Morales-Urrutia et al., 2017). 
En 1975, se formó un contingente de aproximadamente cien soldados mujeres en el Ejército, quienes luego de una formación aproximada de seis meses, se desempeñaron en unidades militares como oficinistas que reemplazarían a los hombres que cumplían estas funciones. Este proyecto fracasó, ya que no se realizó una adecuada planificación, no se disponía de la reglamentación necesaria y no hubo aceptación por parte del personal militar masculino. En consecuencia, este proceso fue rápidamente suspendido (Meza Hernández, 2004).

En 1999, después de varios estudios y análisis en diferentes niveles, las Fuerzas Armadas abrieron la posibilidad de que las mujeres optaran por la carrera militar, dado que ellas ocupan roles importantes dentro de la evolución y desarrollo de la sociedad ecuatoriana (Morales-Urrutia et al., 2017); así, se permitió el ingreso de mujeres a las escuelas de formación de oficiales. El programa propuesto contemplaba que los estudios superiores se debían realizar en las mismas condiciones que los hombres para que ellas lograran el grado de subtenientes. Además, se considera pertinente admitir el ingreso de cadetes mujeres a la Escuela Militar como aspirantes a oficiales de armas de apoyo, de combate y de apoyo de servicio de combate inicialmente. Después de una evaluación a corto y mediano plazo, se consideraría ampliar su acceso a las armas de combate de acuerdo con los resultados obtenidos (Meza Hernández, 2004).

Desde esta época, el ingreso de las mujeres a la institución ha sido permanente; sin embargo, el proceso se ha ido adaptando a las nuevas exigencias sociales de la incorporación y ha sido necesario trabajar varios aspectos institucionales: desde la misma adaptación del grupo femenino frente a sus pares varones, hasta la reglamentación, así como adecuaciones en la infraestructura de las instalaciones existentes (Meza Hernández, 2004).

Las pruebas de ingreso académicas y psicológicas son las mismas para aspirantes hombres y mujeres, pero las pruebas físicas de ingreso para las mujeres son específicas y fueron determinadas de acuerdo con las marcas establecidas en la Academia Militar West Point (Estados Unidos) (Estudio de Estado Mayor, 1999).

En el 2010 fue dada de alta la primera mujer infante de marina. En el 2011 fueron dadas de alta las primeras soldadas especialistas de la Fuerza Terrestre, las primeras oficiales de arma (pilotos), técnicos de la Fuerza Aérea y la primera mujer piloto de ala rotativa de la Fuerza Naval. Asimismo, se abrieron las armas de Artillería e Ingeniería para las mujeres del Ejército. En este mismo año, por primera vez mujeres oficiales participaron en el Curso de Expertos Militares de Misiones de Paz de Naciones Unidas. En el 2012, la Fuerza Aérea Ecuatoriana graduó a las primeras mujeres con infantes aéreas (Ministerio de Defensa Nacional, Ecuador, 2020). 


\section{Historia de la incorporación de las mujeres en el Ejército Nacional de Colombia}

Recapitulando la historia patria de Colombia, la primera mujer que formó parte abiertamente de las Fuerzas Armadas en el país fue Policarpa Salavarrieta, quien sirvió al Ejército Patriota de los Llanos años después del grito de Independencia en 1810. Casi un centenar de años después, en 1932, Clara Elisa Narváez Arteaga se consolidó como la primera mujer soldado y, con tan solo 23 años, participó en la guerra entre Colombia y Perú. 159 años después del fusilamiento de La Pola (44 años después de la partida de Clara Narváez a una misión extra territorial), “el gobierno nacional permitió formalmente, mediante el Decreto 2129 del 7 de octubre de 1976, el ingreso de 12 mujeres al escalafón militar en la categoría de oficial del cuerpo administrativo del Ejército" (Castillo, 2018).

Fue así como, mediante una ceremonia realizada en la Escuela Militar de Cadetes "General José María Córdova”, se llevó a cabo el ascenso al grado de oficiales en el Cuerpo Administrativo de esta docena de mujeres que ingresaron al primer curso mixto de profesionales escalonados, bajo las especialidades de bacteriología, medicina y odontología (Uscátegui, 2015).

Más adelante, en 1983, ingresaron 84 mujeres al primer Curso Femenino de Suboficiales Policarpa Salavarrieta, quienes unos años después obtuvieron el grado de suboficiales del Cuerpo Administrativo. Esta promoción, integrada por 77 cabos segundos, constituyó un ejemplo de valor y espíritu militar, ya que todas las participantes adelantaron simultáneamente el curso de paracaidismo militar (Ejército Nacional de Colombia, 2019).

Cabe agregar que en 1993 el Senado de la República de Colombia aprobó un proyecto de ley para que las mujeres pudieran prestar el servicio militar voluntario en las tareas de apoyo logístico, administrativo, social, cultural o de defensa del medioambiente y, en general, de actividades que contribuyeran a la modernización y al desarrollo del país (Ejército Nacional de Colombia, 2019).

No obstante, en un hecho sin precedentes en el país, para el 2009 se matricularon en la Escuela Militar de Cadetes “General José María Córdova” las primeras 62 mujeres como oficiales de armas. Luego, en el 2012, la sargento mayor Luz Marina Correa Calderón se constituyó como la primera mujer suboficial en ascender a este grado. De la misma manera, para el 2016 ingresaron las primeras mujeres oficiales de las armas de Caballería y Artillería. Luego, en el 2017, se incorporó el primer curso de mujeres como suboficiales de armas. Al siguiente año, en el 2018, por primera vez una mujer militar en la historia de Colombia obtuvo el rango de 
alférez del arma de Infantería. Más recientemente, en el 2020, una militar obtuvo el grado de líder de desminado y oficial del arma de Ingenieros (Ejército Nacional de Colombia, 2019).

\section{Mujeres Oficiales de LAS ARMAS}

Como se mostró en el apartado precedente, hoy por hoy las mujeres ocupan roles en las cuatro armas base de las Fuerzas Militares de Colombia (Infantería, Caballería, Artillería e Ingeniería), y aunque su ingreso a la institución tuvo lugar en las armas del Cuerpo Logístico, Inteligencia y Comunicaciones, hoy en día también apoyan la labor de las armas de Ingeniería, Caballería y Artillería. Del mismo modo, han alcanzado logros en aviación militar, dentro de lo cual se resalta la graduación, en 2018, de la primera mujer piloto del Ejército en comandar aeronaves estadounidenses UH-60 Black Hawk. Más adelante se espera contar también con el valioso servicio del personal femenino en armas contemporáneas, como las Fuerzas Especiales y Acción Integral (Dussán, 2018).

Ahondando en el tema, no cabe duda de que un gran acercamiento a destacar en la búsqueda de inclusión de las mujeres en las Fuerzas Armadas se dio en el mes de enero de 2009, con la incorporación de las primeras 62 mujeres como oficiales de armas, de las cuales en la actualidad 46 ya obtuvieron el grado de capitán, el pasado diciembre de 2019. Según Uscátegui (2015), estas mujeres

fueron seleccionadas entre varios centenares de aspirantes inscritas para formarse como Oficiales de las Armas en Comunicaciones, Logística e Inteligencia militar, es decir un Cuerpo diferente al administrativo, que les exigía una disponibilidad de tiempo completo y una permanencia en la Escuela de cuatro ańos seguidos. (p. 18)

Vale la pena aclarar que en Colombia existen tres escuelas de formación militar: la Escuela Militar de Cadetes "General José María Córdova” — considerada la alma mater del Ejército—, la Escuela Militar de Suboficiales "Sargento Inocencio Chinca”” y la Escuela de Soldados Profesionales. Por esta razón, el ingreso de las mujeres a la carrera de armas en el 2009 marcó un hito importante en una institución de tradición masculina como el Ejército Nacional de Colombia. Desde entonces, tal como afirman Husain y Muñoz (2019), "se empezaron a generar diversas transformaciones dentro de la institución en materia de relaciones de género que buscaban asegurar condiciones de no-discriminación y desarrollo profesional y personal tanto para hombres como para mujeres" (p. 3). 


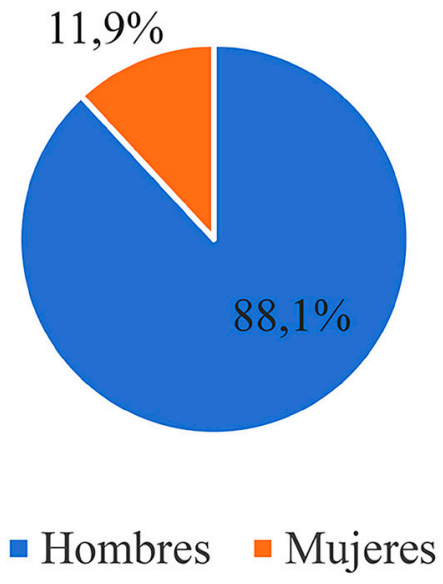

Figura 1. Distribución porcentual de activos en el Ejército de Colombia según género - 2020. Fuente: Comando de Personal (2020)

En la actualidad, Colombia cuenta con 53.527 efectivos militares activos de los cuales 6.363 son mujeres, correspondientes a un 11,9\% del total (figura 1). Ahora bien, en la figura 2 se puede apreciar que las áreas del Ejército de Colombia en las que la participación de las mujeres es superior a la de los hombres corresponden a la Justicia Penal Militar (JPM) con un 53,4\%, el cuerpo administrativo (ADM) con un 62,6\% y el área civil (CIV) con un 61,2\%. De igual manera, se observa la presencia de mujeres como alumnas y cadetes (NA) en un 10,1\%, próximas a retirarse (NA.) 9,0\%, vinculadas a Logística 8,3\%, en Comunicaciones $4,6 \%$ y en las armas de Infantería, Ingeniería, Caballería, Artillería, Inteligencia (IMI), Aviación (AVI) y Fuerzas Especiales (FES) oscila entre el 0 y el 2,6\%.

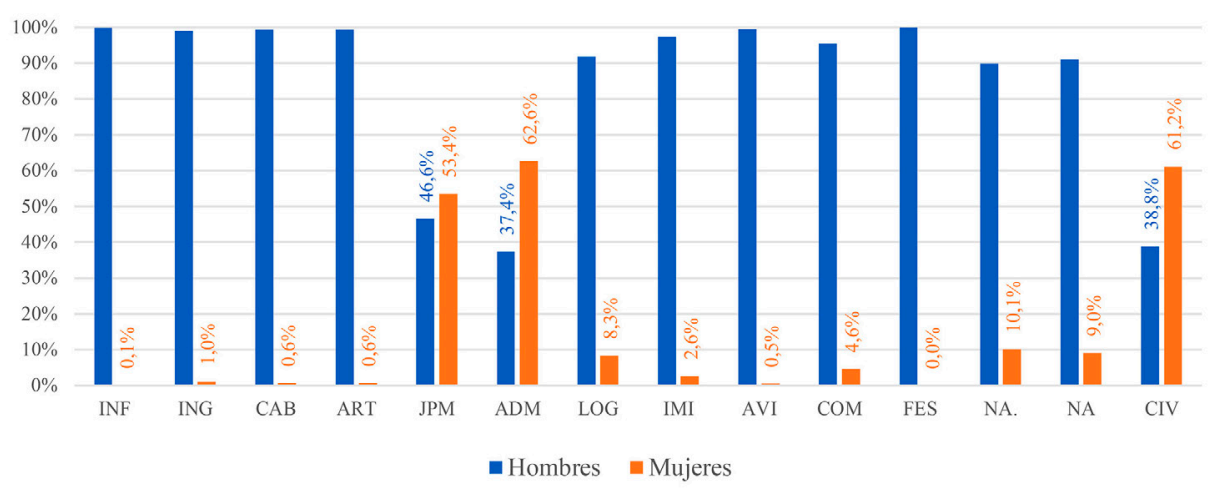

Figura 2. Distribución porcentual de activos en el Ejército según arma y sexo - 2020.

Fuente: Comando de Personal (2020) 
Respecto a los grados alcanzados por las mujeres durante la trayectoria de su incorporación en las Fuerzas Armadas de Colombia, la figura 3 refleja que, a la fecha, existen en el cuerpo de oficiales 370 subtenientes, 283 tenientes, 182 capitanes, 112 mayores, 24 tenientes coroneles, 31 coroneles y 2 mayores generales. Del mismo modo, en el cuerpo de suboficiales hay 234 cabos terceros, 84 cabos segundos, 95 cabos primeros, 280 sargentos segundos, 14 sargentos primeros, 19 sargentos mayores y 2 sargentos mayores de comando (figura 4).

Total de grados oficiales: 9.361

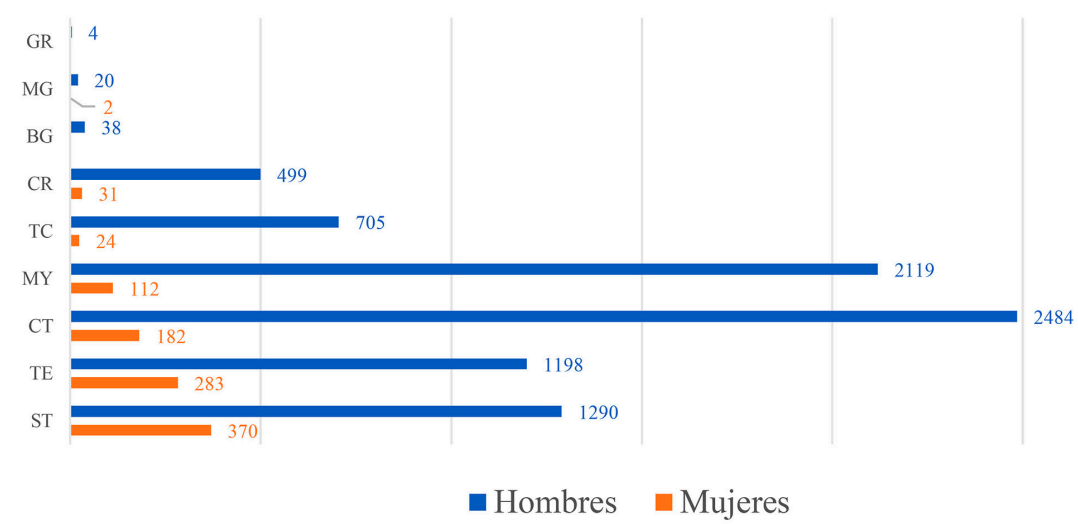

Figura 3. Distribución porcentual de oficiales en el Ejército según arma y sexo - 2020. Fuente: Comando de Personal (2020)

Total de grados de suboficiales: 31.429

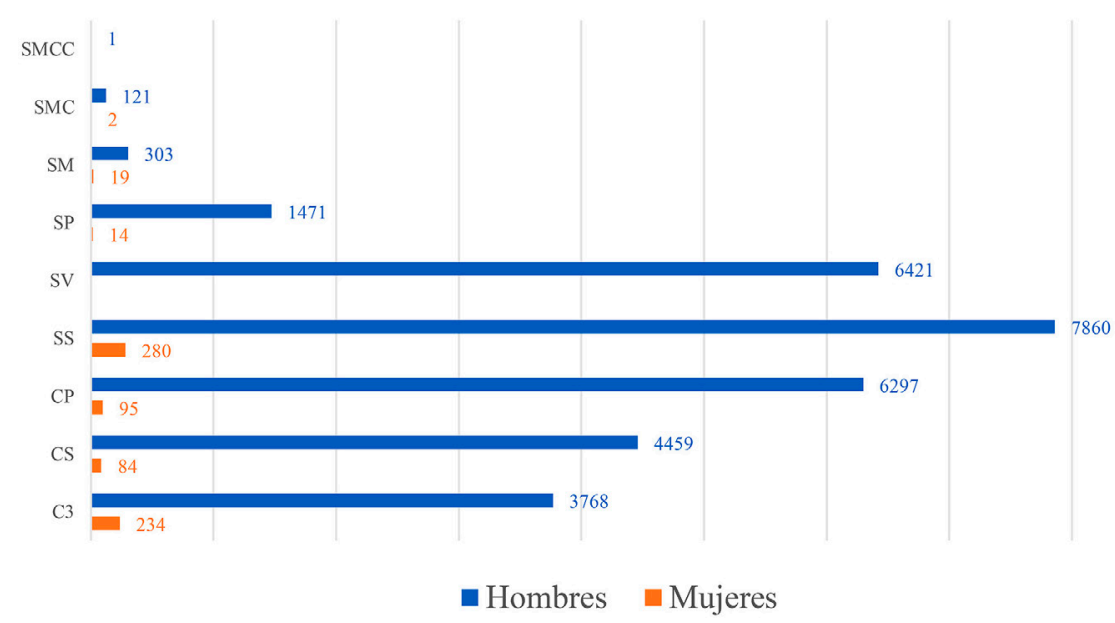

Figura 4. Distribución porcentual de suboficiales en el Ejército según arma y sexo - 2020. Fuente: Comando de Personal (2020) 


\section{El ARMA DE CABALlERÍa}

El arma de caballería siempre ha sido un elemento importante en toda la historia militar, no obstante, durante el Imperio romano y el resto de la Edad Antigua era más utilizada la infantería, las formaciones y las tácticas de combate cuerpo a cuerpo. En Grecia, la caballería de los siglos X a VII a. C. fue el grupo militar que representaba en el campo de batalla a la aristocracia (Salinas de Frías, 2010). Ya a finales del Imperio romano, se utilizaban los caballos como arma de guerra, pero no a gran escala, y no eran tan cruciales a la hora del conflicto, ya que en la Edad Media el caballo era considerado un símbolo de autoridad, por lo tanto, eran solo montados por personas influyentes en los guerreros, como los generales. Es con la caída del Imperio romano que la caballería se convierte en el arma más importante de todo el ejército: la carga se convierte en el elemento más efectivo y además en un símbolo de la nobleza, de poder y fuerza militar. La guerra es una actividad en la que se dan innovaciones rápidamente, ya que la propia vida está en juego.

La caballería dejo de ser efectiva en la época de Napoleón, hacia 1800, cuando se empieza a dar prioridad a la artillería, a los cañones de guerra. De esta manera, los caballos tuvieron mucha importancia durante 1.200 años, desde la caída de Roma hasta la época de Napoleón, cuando empezó la decadencia su uso debido a la llegada de la artillería junto con las armas de fuego que, cada vez más avanzadas, terminarían por sustituir a las cargas. Sin embargo, en la edad contemporánea, en la Segunda Guerra Mundial, aún se emplearon unidades de caballería. "Las más famosas, la de los lanceros polacos, llamada Brigada Pomerania, que fue aplastada por los Panzer nazis. La última carga de caballería en la guerra la realizó el Regimiento Saboya, en Rusia, en 1942” (Uribarri, 2019).

En Colombia, una de las batallas más representativas para el arma de Caballería tuvo lugar el 25 de julio de 1819, con el heroico actuar y apoyo de catorce lanceros del coronel Juan José Rondón a las tropas del Ejército Venezolano-Granadino de Simón Bolívar en su victoria sobre las tropas realistas. Gracias a esta gloriosa intervención, el Ejército Libertador consiguió llegar a la ciudad de Tunja el 4 de agosto del mismo año para lograr la Independencia de Colombia (Ejército Nacional de Colombia, 2019).

Ahora bien, la historia del arma de Caballería en Colombia toma un matiz diferente con la incorporación de las mujeres militares en sus filas, ya que esta actividad, como su nombre lo dice, tradicionalmente era realizada por hombres caballeros. No obstante, gracias al proceso de incorporación de la mujer en la Fuerza Armada, en el 2016 el Ejército colombiano activó su primer Pelotón Montado 
conformado por 25 mujeres, entre oficiales y suboficiales en el departamento del Casanare (Ejército Nacional de Colombia, 2019).

Hoy en día, el arma de Caballería del Ejército Nacional de Colombia cuenta con un total de 18 mujeres subtenientes y 13 más que aún se encuentran en formación en la Escuela Militar de Cadetes; para un total de 31 mujeres oficiales en esta arma (Comando de Personal, 2020). Las mujeres de caballería están dispuestas a aceptar los retos de la manera más profesional y de acuerdo con las capacidades que la misma arma demanda, de manera disciplinada, demostrando por qué escogieron el arma de la gran nobleza que, desde la misma gesta libertadora, demostró su honor, gallardía y amor por la patria. Así como en su momento las mujeres administrativas se desempeñaron en su carrera militar en tal especialidad y gracias a ello llegaron a ser oficiales de insignia por el conocimiento dentro de su área, así mismo se deben proyectar las oficiales de caballería, para desempeñarse durante su carrera militar en el arma de acuerdo con las funciones y responsabilidades de los diferentes grados. Esto tiene como propósito cerrar la brecha que actualmente existe entre los hombres y las mujeres de caballería, de forma que se acompañe su capacitación y formación con la experiencia necesaria para ocupar cargos clave en unidades tácticas como oficiales de operaciones y comandantes.

\section{Retos de la incorporación militar femenina en el arma de Caballería}

A lo largo del documento se ha evidenciado la amplia participación de las mujeres en las Fuerzas Armadas a nivel internacional, regional y local. La decisión de aceptar personal femenino se ha basado en la contribución continua que realizan las Fuerzas Armadas con la sociedad, lo cual permite estrechar aún más las relaciones cívico-militares. Esta decisión se fundamenta en las experiencias favorables de la presencia de la mujer en los diferentes ejércitos, así como en el desarrollo del sistema educativo militar y la capacidad profesional de los miembros de las Fuerzas Armadas para aceptar el reto del ingreso de las mujeres a la institución castrense (Meza-Hernández, 2004).

No obstante, aún existen limitantes para el pleno acceso de la mujer a los diferentes cuerpos, armas o especialidades del ejército, según el país. En Latinoamérica actualmente solo los ejércitos de Colombia, Paraguay y Uruguay permiten la vinculación de la mujer de forma cabal a todas las diferentes armas y especialidades de sus Fuerzas Armadas.

Sin embargo, el ingreso de las mujeres en las Fuerzas Armadas es solo un aspecto a considerar en el análisis, ya que limita el estudio a la mera obtención de datos cuan- 
tificables atendiendo al aspecto formal de la incorporación, sin llegar a profundizar sobre la "calidad" de la misma desde la perspectiva de género. Este paso, no obstante, permite obtener una primera impresión sobre la "visibilidad de la mujeres" dentro de los ejércitos. (Lucero, 2009, p. 44)

Del mismo modo, al fijar la atención en el panorama nacional, la investigación realizada por Cuenca (2015) revela que existen disyuntivas sobre la presencia de las mujeres en la institución. En dicho estudio, algunos hombres militares activos se niegan a la debida integración de las mujeres, especialmente, en el cuerpo de las armas, ya que, según ellos, la transición realizada por el personal militar femenino en la institución no ha sido la adecuada. Al respecto afirman que, a pesar de que es igual el nivel de dificultad física y mental de los entrenamientos, así como reciben la misma capacitación, costos, tiempo y dedicación, a la hora de llegar a las unidades solamente los hombres "salen a patrullar" mientras que las mujeres se limitan realizar funciones más administrativas que operativas. Esto implica caer en un grave error, ya que si se continúa aislando a las mujeres de ejercer labores como la de comandar un pelotón, ellas nunca van a adquirir la debida experiencia que exigen los cargos y grados, de forma que no podrán igualar sistemáticamente las funciones de los oficiales hombres (Cuenca, 2015).

Al respecto, Donadio y Mazzotta (2016) asocian la existencia de diferencias en la cohesión laboral entre hombres y mujeres militares con el "concepto de tokenismo, presente cuando se plantea la incorporación de la mujer como una verdadera inclusión, y en la realidad esta es aparente” (p. 9). A lo cual añaden que un ejemplo de ello es la excesiva aparición y realce de los logros de las mujeres en las filas militares para crear en la sociedad un imaginario colectivo de los grandes avances en materia de "igualdad de oportunidades, mientras que en la práctica las posibilidades de optar y avanzar en las mismas direcciones y condiciones que el personal masculino no son equivalentes" (p. 14).

Por otro lado, Cuenca (2015) manifiesta que el lenguaje juega un papel fundamental en la búsqueda de una verdadera equidad y armonía entre militares hombres y mujeres. Este lenguaje simbólico expresado en himnos, lemas, rituales e insignias militares se apoya en una cultura que se caracteriza por discursos patriarcales, que han sido elaborados desde las primeras batallas libradas para la Independencia, como la Batalla de Boyacá, con el objetivo de preparar mentalmente a los hombres militares para la guerra, en especial en las armas más tradicionales del Ejército como son la Caballería y la Infantería. Todas estas expresiones hacen referencia meramente a la masculinidad mediante palabras que buscan elevar el ego de los hombres y hacerlos sentir en la capacidad de dominar a otros sujetos, incluyendo las mujeres. 
Estas expresiones lingüísticas que pretenden reflejar una superioridad naturalizada del género masculino aumentan aún más la brecha de la equidad y continúan supeditando a las mujeres en el ámbito militar.

\section{Discusión}

Esta investigación tuvo como propósito analizar si la cultura y tradición del Ejército Nacional, en especial en el arma de Caballería, se encuentra preparada para aceptar a la mujer oficial en igualdad de condiciones y proporciones que un hombre oficial. De igual manera, se pretendió indagar cómo ha sido la incorporación de las mujeres en las fuerzas armadas en el contexto internacional y, a su vez, describir desde el contexto nacional el proceso histórico de inclusión de las mujeres en el Ejército Nacional de Colombia, para finalmente evaluar los aspectos que dificultan la equidad de género entre los hombres y mujeres que conforman las filas de esta institución militar en el país. A continuación, se estarán discutiendo los principales hallazgos de este estudio, teniendo en cuenta que estos pueden ser utilizados para posteriores estudios relacionados con el tema.

La investigación adelantada por Robelo (2015) presenta serios conflictos laborales entre efectivos militares, en los que los hombres todavía no logran tener una visión de "par" hacia las mujeres, les cuesta trabajo aceptar su estilo de liderazgo o comunicación, ya que lo consideran diferente al que ellos ya están acostumbrados. Esta situación se asimila a los resultados obtenidos por el presente estudio, en los que se demuestra que el proceso de inclusión de las mujeres, especialmente en el cuerpo de las armas en el Ejército Nacional de Colombia, ha generado una serie de conflictos internos en la institución. En efecto, un grupo de hombres tampoco asimila de manera positiva el escalonamiento militar de las mujeres, pues se evidencia que menos del $3 \%$ hacen parte de las filas en armas tradicionales como Caballería, Artillería, Infantería e Ingeniería.

Por su parte, en la investigación publicada por De la Hoz (2018) se demuestra que los inicios de la incursión femenina en las Fuerzas Armadas Españolas se dieron en áreas de servicios de salud, con la creación del Cuerpo de Damas de Sanidad Militar. Lo mismo ocurrió en México, como lo refiere Félix (2020): el primer acercamiento de la mujer a las Fuerzas Armadas de este país, de acuerdo con los registros históricos, fue realizada por la Madre Cuca, Refugio Estévez Reyes, nombrada sargento enfermera por el general Urriza en 1906. Los mismos resultados se observan en el trabajo investigativo de Rojas et al. (2017) con el ingreso en Colombia de las primeras doce mujeres como oficiales de la Escuela Militar de 
Cadetes “General José María Córdova” en 1976, para desempeñarse en el área de la salud, en especialidades como bacteriología, medicina y odontología.

Para continuar la discusión de los resultados, se hace referencia a la investigación de Lucero (2009), en la que se destaca el avance de las Fuerzas Armadas de Argentina, al crear la política pública para la mujer militar en la Secretaría de Defensa Nacional. Así mismo, allí se menciona la creación de organismos que se encargan de analizar, dar manejo y solución a los diferentes conflictos que se presenten respecto al género para garantizar el debido desarrollo de las mujeres en el Ejército. Esta situación no se observa en Colombia, ya que, al igual que en México, la incorporación de la mujer en la milicia no es directamente proporcional a los adelantos en materia de legislación para la equidad de género.

En el contexto nacional es de resaltar que la mujer oficial de Caballería tiene una formación militar de cuatro años en la Escuela Militar, donde se realizan ejercicios tácticos de terreno, curso avanzado de combate, fase de mando en igualdad de condiciones que sus compañeros de curso (hombres). No obstante, es imperativo que los comandantes de grupo empoderen y den responsabilidades a estas oficiales para que adquieran experiencia en el mando y exploten las capacidades que adquirieron en la escuela de formación.

Igualmente se ha podido proyectar que, en el futuro y de acuerdo con el plan de carrera que se ha diseñado por parte del Comando de Personal, se debe tener en cuenta que la evaluación y clasificación de los oficiales debe ser por igual para todos los integrantes del arma de Caballería, en donde se les debe evaluar todas sus capacidades en conjunto. Así mismo, se debe calificar su desempeño como comandantes de pelotón y comandantes de escuadrón en los grados de oficiales subalternos, pues esto aportará experiencia para que la oficial pueda desempeñarse en los cargos de dirección, como oficial de operaciones, ejecutivos y segundos comandantes y, posteriormente, comandantes de grupo, ya que la historia nos confirma que la experiencia continua asegura el éxito en los cargos.

No obstante, no es posible pensar que los cambios necesarios para hablar de igualdad efectiva en los ejércitos van a tener lugar de un día para otro. En efecto, el proceso de adaptación requiere de esfuerzos mancomunados — que partan del aprendizaje por parte de las instituciones - y del esfuerzo por la integración que deban realizar los miembros de las Fuerzas Armadas, para lo cual no basta con una simple posición de tolerancia hacia las mujeres que ingresan, sino que es necesario que todas y todos trabajen por y para la integración real (Martín Martínez, 2009). 


\section{Conclusiones}

La incorporación de la mujer en las Fuerzas Militares se originó, en primer lugar, por el deseo que emerge de algunas de ellas de convertirse en agentes de cambio y desarrollo para aportar a la transformación social. La historia muestra que en un principio se fueron vinculando una a una de manera informal, voluntaria y altruista, para ser parte o liderar la lucha por la defensa de una causa justa. Así se dan a conocer hechos emblemáticos, como en Estados Unidos y España, donde las mujeres no solo se vinculaban a la guerra como apoyo moral o sanitario, sino que tenían la osadía de ocultar su verdadera identidad femenina con tal de enlistarse en las filas de combate a la par con los hombres.

En segundo lugar, la inclusión militar femenina masiva obedece a los lineamientos ideológicos que rigen organizaciones mundiales en búsqueda de la equidad de género, la eliminación de toda forma de discriminación hacia la mujer y la real necesidad operativa de contar con el apoyo femenino, en un principio, en áreas administrativas y logísticas, y paulatinamente en todos los cuerpos de las Fuerzas Militares, incluyendo las armas más tradicionales como Caballería o Infantería. De esta manera, países miembros de la Organización del Tratado del Atlántico Norte (OTAN), como Estados Unidos, Francia y España, cuentan con un promedio del $11 \%$ de participación de mujeres en sus ejércitos (un promedio bastante superior al de Colombia). A nivel latinoamericano, Argentina también representa un claro ejemplo de inclusión femenina en las Fuerzas Armadas, al incorporar gradualmente legislación en políticas públicas para las mujeres militares, lo cual ha permitido una mejor comprensión de la dinámica de perspectiva de género en la institución militar.

Ahora bien, Colombia actualmente es uno de los pocos países que permiten la incorporación de la mujer en todos los cuerpos y armas del Ejército Nacional (Caballería, Artillería, Infantería e Ingeniería, además del cuerpo administrativo, Comunicaciones, Inteligencia, Logística y Aviación), para un total de 6.363 mujeres entre oficiales, suboficiales y civiles. Esto corresponde a un porcentaje del 11,9 sin discriminar la participación de mujeres en el cuerpo administrativo y en el cuerpo de armas (caso en el que el porcentaje de mujeres que participa en la carrera militar no alcanza el $5 \%$ ), que, aunque a primera vista denota un rezago en temas de equidad respecto a los hombres $(88,1 \%)$, en realidad es el resultado de un arduo proceso que se remonta a 1976, cuando ingresaron las primeras doce mujeres al escalafón de oficiales en la especialidad de bacteriología, medicina y odontología.

En consecuencia, es totalmente necesario emplear a las mujeres oficiales de Caballería en los cargos para los que fueron entrenadas y capacitadas, debido a que se 
ha evidenciado que hay oficiales que cumplen tareas administrativas u otro tipo de tareas ajenas a la especialidad. Esta situación afecta gravosamente a la oficial, que no puede ejercer el mando que es requisito para lograr su ascenso. Además, se afecta el arma, que empieza a perder cuadros de mando en unidades donde las Tablas de Organización y Equipo (TOE) no son funcionales, ya que no hay comandantes de pelotón con el entrenamiento adecuado para asumir el cargo.

$\mathrm{Al}$ no permitir que las oficiales del arma de Caballería cumplan con el desempeño en las diferentes especialidades en los grados subalternos, se incide en futuros fracasos operacionales debido a la falta de experiencia al momento de recomendar y orientar las operaciones en las unidades tácticas. Es necesario tener presente que un oficial superior debe tener el conocimiento sólido para desempeñarse de manera eficiente, lo cual cuenta, en primer lugar, para proteger la vida del personal a cargo y, en segundo lugar, para lograr una mayor efectividad en el desarrollo de las operaciones al mantener siempre el material y equipo en óptimas condiciones. Por ese motivo, los cargos en la institución se estipulan de acuerdo al grado; de igual manera, al momento de ser evaluados tanto los hombres como las mujeres para ascender a los grados inmediatamente superiores, no se van a generar criterios diferentes, sino que, al contrario, van a ser calificados de forma equitativa y justa. Este proceso de cambio para la plena inclusión femenina en el Ejército Nacional tiene importantes consecuencias para todo el personal militar y prevé implicaciones en ámbitos culturales y sociales nacionales.

Por último, al analizar el avance en el proceso de incorporación desde la óptica de la equidad de género, se concluye que, aunque las mujeres han alcanzado grandes logros en materia de escalonamiento y adhesión a las Fuerzas Armadas de Colombia, aún existen y persisten grandes retos que desafían a un cambio de paradigma en la cultura y tradición del Ejército Nacional, en especial, en el cuerpo de las armas. Se evidencia que, a pesar de que hombres y mujeres reciben por igual la formación, sin ningún tipo de discriminación, a la hora de conformar unidades la institución no asigna a la mujer a las labores operativas, como la de comandante de batallón, sino que continúan la misma línea patriarcal en la que el personal militar femenino es supeditado a participar netamente en asuntos administrativos, tecnológicos o logísticos; de esta forma se perpetúa el tabú estereotipado de que la guerra es cosa de hombres, un asunto que requiere fuerza y destreza física para la cual la mujer no se encuentra preparada y no puede competir en igualdad de condiciones y proporciones al hombre.

Lo anterior es el claro reflejo de la ausencia de una debida ejecución de políticas públicas tendientes al desarrollo de las mujeres militares en igualdad de condi- 
ciones a los hombres, puesto que el Ministerio de Defensa Nacional de Colombia creó la "Política pública sectorial de transversalización del enfoque de género para el personal de la Fuerza Pública” en el año 2018, proyectado hacia el 2027. En este sentido, se evidencia un avance tardío en comparación a las fechas de iniciación de las mujeres en las Fuerzas Militares del país.

Aunque es comprensible que este tipo de procesos requiere de tiempo, urge que en la realidad sea llevado a cabo un plan de acción estructurado, trasversal e incluyente, que sea viable, coherente y sostenible en el tiempo. Cabe anotar que el hecho de limitar a las oficiales a ejercer labores operativas también se constituye como discriminación, que se traduce en insatisfacción y desmotivación laboral no solo para las mujeres, sino también para los hombres oficiales, quienes, al igual que ellas, demandan una equidad de género que garantice la debida formación práctica de sus compañeras de armas.

\section{Referencias}

Agrelo, G. (2016). Diagnóstico de la capacitación del oficial del ejército y su alineación con el análisis ocupacional y el momento de la carrera [Trabajo de grado]. Escuela Superior de Guerra del Ejército, Perú.

Alioni, A. (2016). Reflexiones acerca del carácter de la incorporación de mujeres a la institución militar en Argentina. En C. García-Gil, C. Flecha García, M. J. Cala Carrillo, M. Núñez Gil, \& A. Guil Bozal (Eds.), Mujeres e investigación. Aportaciones interdisciplinares. VI Congreso Universitario Internacional "Investigación y Género". Universidad de Sevilla. https://idus.us.es/ handle/11441/52136

Bustamante, S. B. (2012). The role of women and gender in conficts: General catalogue of official publications. Spanish Ministry of Defence. http://www.ieee.es/en/Galerias/fichero/cuadernos/ CE_157_B_TheRoleofWomenandGenderinConflicts.pdf

Caballud Hernando, M. B. (2014). Aportación de la mujer militar en las fuerzas armadas espańolas a la defensa y la seguridad. Arbor: Ciencia, Pensamiento y Cultura, 190(765), 1-7. http://dx.doi. org/10.3989/arbor.2014.765n1006

Camacho, C., \& Cabrera, M. (2015). Ejército, feminidades y géneros performativos: las experiencias de ser mujer y militar en la Escuela General de Cadetes "General José María Córdova" [Tesis de maestría, Pontificia Universidad Javeriana]. Repositorio Institucional. https://repository.javeriana.edu.co/ handle/10554/14323

Carreiras, H. (2018). La integración de género en las Fuerzas Armadas, condicionamientos y perspectivas. Nueva Sociedad.

Castillo, M. (2018). Así se han incorporado las mujeres a la fuerza pública. Semana. https:// www.semana.com/contenidos-editoriales/fuerzas-armadas-marcha-hacia-la-paz/articulo/ asi-se-han-incorporado-las-mujeres-a-la-fuerza-publica/574805

Cely, M. (2019). Configuración de los roles de género en mujeres pertenecientes al Ejército Nacional de Colombia y sus implicaciones en el sistema familiar [Tesis de pregrado, Universidad Externado de Colombia]. Repositorio Institucional. https://bdigital.uexternado.edu.co/handle/001/2336 
Coleman, M. (2016). Women in the Military. PowerKids Press.

Comando de Personal del Ejército. (2020). Boletín informativo gráfico "mujeres del arma de Caballería oficiales” [Boletín n. ${ }^{\circ}$ 16]. https://www.coper.mil.co/comando_personal/actualidad/boletines_485098_485098

Cuenca, Y. (2015). La participación de algunas mujeres en el Ejército Nacional de Colombia. Revista Manzana de la Discordia Univalle, 6(2), 57-63.

De la Hoz, M. (2018). La mujer en las Fuerzas Armadas de Colombia y España: agente de reconstrucción social durante el posconflicto [Tesis de pregrado, Universidad Católica de Colombia]. Repositorio Digital Universidad Católica de Colombia. https://repository.ucatolica.edu.co/ handle/10983/15790

De la Rosa, M. (2019). La mujer en el ejército mexicano. Mugs Noticias.

Donadio, M. (2015). La incorporación de la mujer en las fuerzas armadas de la Argentina. Latin American Studies Association.

Donadio, M., \& Mazzotta, C. (2016). La mujer en las instituciones armadas y policiales: Resolución 1325 y operaciones de paz en América Latina.

Dunivin, K. (1997). Military culture, a paradigm shift? Air War College; Air University.

Dussán, Y. (2018). Ejército gradúa a primera mujer piloto de Black Hawk. Diálogo: Revista Militar Digital. https://dialogo-americas.com/es/articles/colombian-army-graduates-first-female-blackhawk-pilot/

Ejército de España. (2018). Mujeres de armas tomar. Ministerio de Defensa de España.

Ejército Nacional de Colombia. (2019). Las armas de nuestro Ejército Nacional. https://www.ejercito. mil.co/?idcategoria $=383645$

Epdata. (2019). Mujeres militares en el ejército, datos y estadistica. Observatorio militar para la igualdad entre mujeres y hombres. Buenos Aires.

Esquivel, R., \& Rodríguez, D. (2015). Nuevas tareas militares de la mujer en el mundo y en Colombia. Escuela Superior de Guerra.

Estudio de Estado Mayor. (1999). Conveniencia del ingreso de cadetes de sexo femenino a la Escuela Superior Militar como aspirantes para arma y servicios. Dirección de Educación de la Fuerza Terrestre.

Félix, P. (2020). Las mujeres militares en México. ElUniversal.com. https://www.eluniversal.com.mx/ opinion/paola-felix-diaz/las-mujeres-y-el-ejercito

Fonseca, D. (2017). ¿La cultura contribuye a la desigualdad de oportunidades laborales entre hombres y mujeres? [Tesis de pregrado, Universidad Simón Bolívar]. Repositorio Universidad Simón Bolívar. https://bonga.unisimon.edu.co/handle/20.500.12442/2214

Gallardo, P. (2018). La mujer militar en las fuerzas armadas. Cuadernos de Estrategia, 157, 139-174.

Gómez, R. (2015). El rol de la mujer en las Fuerzas Armadas, desde la óptica de los colegios de Defensa de Iberoamérica. Jefatura Logística del Ejército Nacional de Colombia.

Gutiérrez Valdebenito, O. (2000). La mujer y las Fuerzas Armadas. Revista de Marina, 117(859), 1-14.

Husain, S., \& Muñoz, L. (2019). Caracterización del liderazgo femenino en ámbitos militares. Reflexiones a partir de las experiencias de las alféreces en su fase de mando. Cuadernos Pagu, 56, 1-28. 
Lucero, M. (2018). La larga marcha de las mujeres en las Fuerzas Armadas latinoamericanas. Revista Nueva Sociedad, 278. https://nuso.org/articulo/la-larga-marcha-de-las-mujeres-en-las-fuerzas-armadas-latinoamericanas/

Lucero, M. R. (2009). Las mujeres en las Fuerzas Armadas Argentinas. Breve Análisis sobre su participación y estado actual de la situación. Unisci Discussion Papers, 20, 36-50.

Martín Martínez, V. (2009). Las mujeres en los ejércitos europeos y latinoamericanos. En M. Gómez Escarda, \& Sepúlveda Muńoz, I. (Eds.), Las mujeres militares en España (1988-2008). Instituto Universitario General Gutiérrez Mellado - UNED.

Medellín, J. (2018). Ya son más de 23.000 las mujeres en las filas del Ejército Mexicano. Defensa.com. https:/www.defensa.com/mexico/ya-son-mas-23-000-mujeres-filas-ejercito-mexicano

Meza Hernández, G. (2004). Rol de la mujer en las fuerzas armadas del Ecuador y su participación en las actividades militares [Tesis de pregrado]. FLACSO, sede Ecuador.

Ministerio de Defensa de Argentina. (2019). 8 de marzo: la mujer en el Ejército Argentino. https:// www.argentina.gob.ar/noticias/8-de-marzo-la-mujer-en-el-ejercito-argentino

Ministerio de Defensa de España. (2018). 30 años de la incorporación de la mujer en las Fuerzas Armadas. Fundación Telefónica.

Ministerio de Defensa Nacional, Ecuador. (2020). Fuerzas Armadas fortalecen sus filas con mujeres en la carrera militar. https://www.defensa.gob.ec/fuerzas-armadas-fortalecen-sus-filas-con-mujeres-en-la-carrera-militar/

Morales-Urrutia, X., Barba-Cevallos, R., González-Herrero, C., Zapata-Guerrero, J. C., \& NoroñaGallo, D. (2017). Mujeres en las fuerzas armadas: el caso del ejército ecuatoriano. Revista de Ciencias de Seguridad y Defensa, 2(4), 125-131.

Olmo, G. (2017). Las mujeres militares de la OTAN, mucho más que cuestión de igualdad. ABC Internacional.

Ricoy Casas, R. M. (2006). La difícil presencia de la mujer en las Fuerzas Armadas: de la mera prohibición al techo de cristal para su promoción y ascenso en un mundo tradicionalmente masculino. Dossiers Femnistes, 9, 225-243

Robelo, F. (2015). La inserción laboral de la mujer en el ejército argentino. Universidad Argentina de la Empresa.

Rojas, J., Piraquive, H., Arango, D., Sequera, N., Guevara, J., \& Pantoja, Y. (2017). Fuerzas Militares de Colombia, Ejército Nacional V División [Documento de investigación, Universidad del Rosario]. Repositorio Institucional de la Universidad del Rosario. https://repository.urosario. edu.co/handle/10336/14150

Salinas de Frías, M. (2010). Sobre algunos textos clásicos referentes a la caballería de los celtíberos y al simbolismo de sus armas. Gladius, 30, 137-154. https://doi.org/10.3989/gladius.2010.0007

Secretaría de Defensa Nacional de México. (2019). Mexicanas al grito de la guerra: las mujeres en la Revolución y el ejército. Televisa News.

Uribarri, F. (2019). La vanidad acabó con la caballería. XLSemanal.com. https://www.xlsemanal.com/ conocer/historia/20190403/caballeria-armas-historia.html

Uscátegui, M. (2015). Mujeres Arr [Tesis de pregrado]. Pontificia Universidad Javeriana.

Ventura, F. (2015). Género, identidad y performatividad en Judith Butler. Universidad de la Laguna. 